\title{
Wideband Directional Base-station Antenna with Dual-linear and Circular-polarization Capabilities
}

\author{
Francisco Lerma \\ Technological University Dublin \\ Matthias John \\ Technological University Dublin, matthias.john@tudublin.ie \\ Giuseppe Ruvio \\ Chelton Microwave Corporation
}

See next page for additional authors

Follow this and additional works at: https://arrow.tudublin.ie/engschececon

Part of the Electrical and Computer Engineering Commons

\section{Recommended Citation}

Lerma, F. et al. (2006) Wideband directional base-station antenna with dual-linear and circular-polarization capabilities. Irish Signals and Systems Conference, pp.253-256. Dublin, 28-30 June, 2006, doi:10.21427/ D7W59D

This Conference Paper is brought to you for free and open access by the School of Electrical and Electronic Engineering at ARROW@TU Dublin. It has been accepted for inclusion in Conference papers by an authorized administrator of ARROW@TU Dublin. For more information, please contact arrow.admin@tudublin.ie, aisling.coyne@tudublin.ie,gerard.connolly@tudublin.ie.

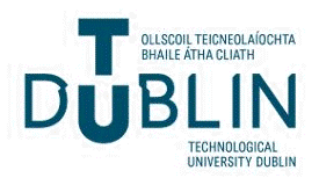




\section{Authors}

Francisco Lerma, Matthias John, Giuseppe Ruvio, Max Ammann, and N. Herscovici 


\title{
Wideband Directional Base-Station Antenna with Dual-linear and Circular-Polarization Capabilities
}

\author{
F. Leon-Lerma ${ }^{*}$, M. John ${ }^{\theta}$, G, Ruvio ${ }^{\theta}$, M. J. Ammann ${ }^{\theta}$ and N. Herscovici, ${ }^{\phi}$ \\ ${ }^{\theta}$ Centre for Telecommunications Value-chain driven \\ Research, \\ *School of Electronic \& Communications \\ Engineering, \\ Dublin Institute of Technology, \\ IRELAND \\ E-mail: ammann@ieee.org \\ ${ }^{\phi}$ Chelton Microwave Corp. \\ Atlantic Division \\ Bolton, MA 01740 \\ E-mail: tuli@ieee.org
}

A crossed-dipole antenna providing polarization diversity is presented. The antenna which employs a planar reflector yields high directivity and good isolation between ports over a wide impedance bandwidth, suitable for polarization-agile wireless base-station use. The dipole wing shape is optimised, which yields the wide bandwidth. Matching is achieved using a quarter-wave balanced-tounbalanced section which also improves the port-to-port isolation. Radiation characteristics for linear and circular polarizations are presented.

\section{INTRODUCTION}

The continued growth in wireless communication systems is increasing the demand for low-cost microwave components and antennas. The crosseddipole antenna, printed on low-cost FR4 substrates is often used as radiating elements for network-point and base-station and antennas [1-4]. In this paper a printed crossed-dipole antenna operating in the $2.45 \mathrm{GHz}$ wireless and ISM (industrial, scientific and medical) band is presented experimentally. The polarization diversity is obtained due to the spatial orthogonality of the two printed dipole antennas. A quarter wave balanced-to-unbalanced resonant line section is used for matching and to improve both the the impedance bandwidth and the isolation between orthogonal elements of the dipole. The antenna is fed using microstrip feedlines, which are placed normal to the dipole wing. The two isolated feed ports can then be excited in various ways to launch linear polarizations with $\pm 45 \circ$ tilt or circular polarizations with right-hand or left-hand sense.

\section{ANTENNA STRUCTURE}

The proposed wing shape of the dipole reduces the shunt capacitance at the gap. The impedance of short thick dipoles is smaller than that of thin dipoles with the same overall dimensions [5]. By using Schelkunoff's method [6], it is known, that for a cylindrical dipole, a broader impedance bandwidth can be obtained by increasing the diameter. This also applies to planar structures [7]. The antenna is fabricated on a circular piece of FR4 laminate of $1 \mathrm{~mm}$ thickness and radius $r=30 \mathrm{~mm}$. The relative permittivity is 4.3 in this frequency range. The dipole wing length $l=17 \mathrm{~mm}$, the gap between dipole wings $g=6 \mathrm{~mm}$. The maximum width of the wing $w=12 \mathrm{~mm}$, which occurs at a distance $l 2=6.3$ $\mathrm{mm}$ from the end of the wing, as shown in Figure 1.

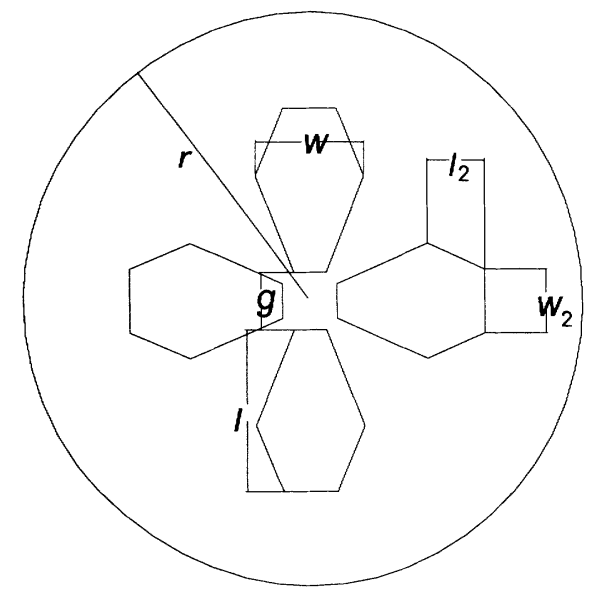

Figure 1. Dimensional layout for the printed crossed-dipole antenna 
A parasitic planar reflector $(70 \mathrm{~mm} \times 70 \mathrm{~mm} \times 1 \mathrm{~mm})$ is centrally mounted at the base of the structure and placed at a distance of $\lambda_{0} / 4$ from dipoles. The quarterwave balanced-to unbalanced (balun) transformer was chosen for the feed system. The dipole is fed using two vertical elements connecting each dipole with the ground plane. Each vertical element comprises a shorting strip and an impedance transformer realized by employing a tapered microstrip line. The microstrip ground is connected to one of the dipole wings and the feed is connected to the opposite wing via a bridge as shown in Figure 2. The balun is based on the well-known resonant line section terminated by short circuit. Its double purpose is to transform the unbalanced current distribution of the input transmission line into the balanced one of the dipole while an impedance match is also provided.

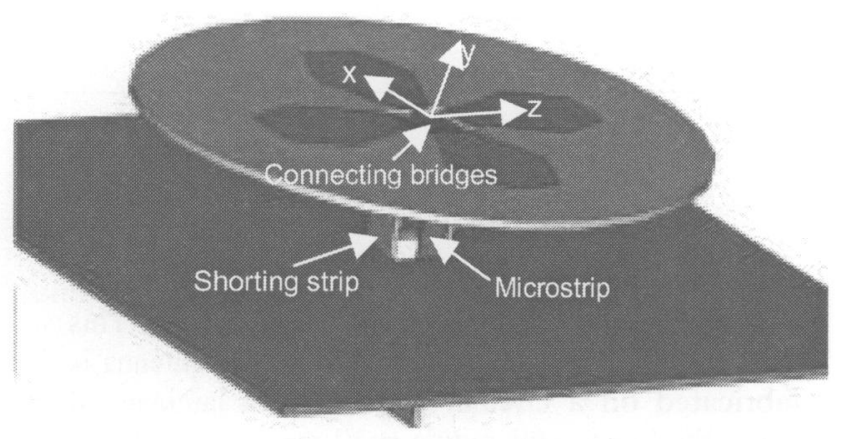

Figure 2. Dipole feed arrangement and coordinate system.

\section{NUMERICAL ANALYSIS}

The finite integration time-domain technique using CST Microwave Studio was used to simulate the structure. The influence of the relative permittivity of the dielectric substrate on the dipole resonant frequency was investigated. It can be seen from Figure 3, that at $2.45 \mathrm{GHz}$, the overall dipole length is reduced from $49 \mathrm{~mm}$ in free-space to $41 \mathrm{~mm}$ when printed on $1 \mathrm{~mm}$ thick FR4 (standard PCB material) substrate (er=4.3) which has a loss tangent of 0.2 . This is based on simulation for a straight dipole wing of width $6 \mathrm{~mm}$. The dielectric effect increases the electrical length. It also reduces the bandwidth of the dipole as shown in Figure 4. It can be seen that maximum bandwidth is achieved in free-space. The bandwidth achievable when printed on a laminate of relative permittivity 4.3 is 370 $\mathrm{MHz}$, according to simulated results. This is somewhat less than the free-space value, but the reduced size is necessary.

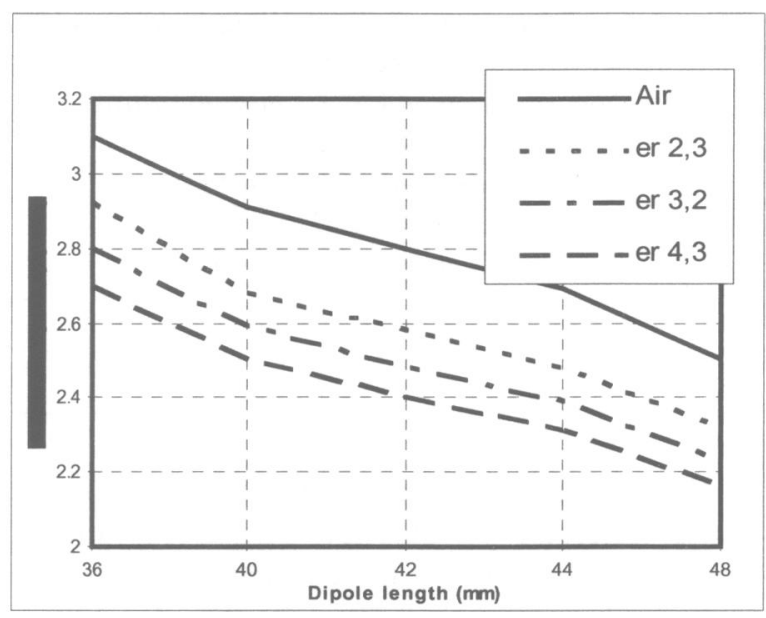

Figure 3. Simulated dipole length plotted against resonant frequency for different values of relative permittivity of the PCB on which the dipole is fabricated.

The proposed optimised wing shape also yields a shorter overall length of $39 \mathrm{~mm}$. The wing shape combines the features of thick dipoles and biconical dipoles, which exhibit a broad bandwidth and a low profile.

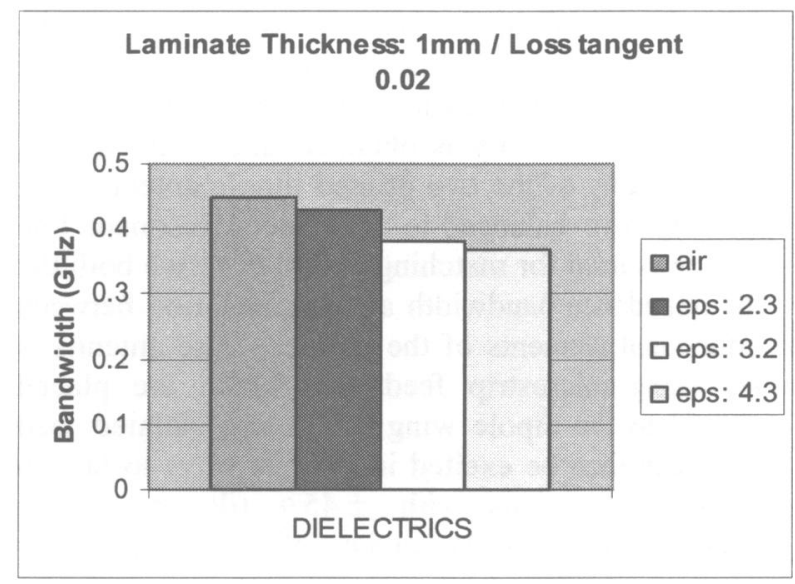

Figure 4. The effect of printing the dipole on dielectric laminate is plotted against impedance bandwidth, for different values of relative permittivity. 


\section{MEASUREMENTS}

\section{Impedance and isolation}

In order to achieve dual linear polarization or circular polarization, it is necessary to have 2 dipoles oriented orthogonally. In this case, the crossed dipoles structure is used, and a quadrature phase arrangement can be used to achieve circular polarization and two independent feeds used for dual linear polarization. When using cross-polarized dipoles, the isolation between dipole ports is a difficult and very important parameter to achieve. Generally, a $20 \mathrm{~dB}$ isolation between ports is necessary for polarization diversity. Otherwise, problems with pattern squint and crosstalk can arise. Optimizations and trade-offs were made in order to get a good compromise between return loss and isolation. It can be seen in Figure 5 that the measured $10 \mathrm{~dB}$ return loss (S11 and $\mathrm{S} 22)$ is achieved from about $2.25 \mathrm{GHz}$ to $2.7 \mathrm{GHz}$, yielding an impedance bandwidth of greater than $450 \mathrm{MHz}$ (more than 18\% fractional impedance bandwidth) for both ports. The measured isolation (S12 and $\mathrm{S} 21$ ) is better than $20 \mathrm{~dB}$ for most of the bandwidth, i.e. from $2.35 \mathrm{GHz}$ to $2.55 \mathrm{GHz}$. This includes the wireless ISM band ( 2.40 to $2.488 \mathrm{GHz}$ ).

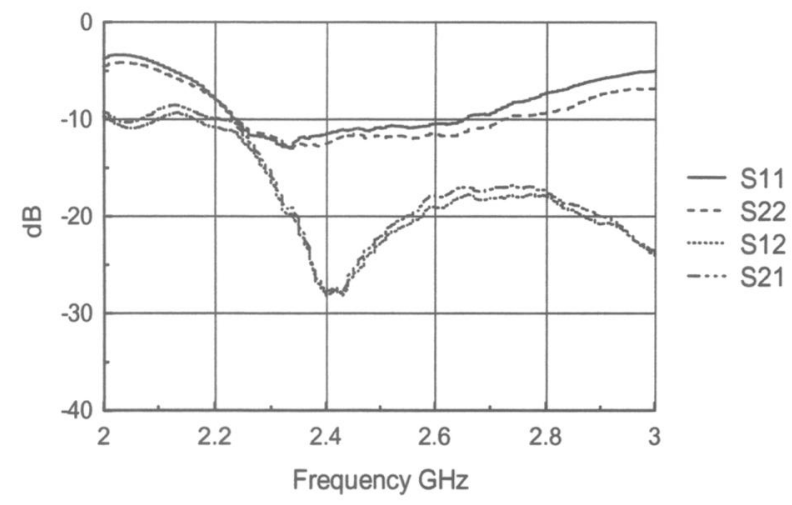

Figure 5. Measured impedance bandwidth and isolation between ports for the crossed dipole antenna.

\section{Radiation characteristics}

The radiation patterns were measured in an anechoic chamber at $2.45 \mathrm{GHz}$ for both polarizations. Figure 7 shows the measured pattern for the $x y$ plane, while the $y z$ plane is shown in Figure 8 . These may be configured in the \pm 45 degree planes, instead of vertical/horizontal which would provide propagation advantages in flat regions. The linear crosspolarization rejection levels are better that $20 \mathrm{~dB}$ on boresight and the front-to-back ratios are in excess of $20 \mathrm{~dB}$ for both planes. A larger groundplane would improve this, if necessary. The patterns are normalised to maximum measured gain, which was $6.5 \mathrm{dBi}$ for both polarizations. A $10 \mathrm{~dB}$ per division scale is used. The gain was measured with a calibrated pyramidal horn antenna.

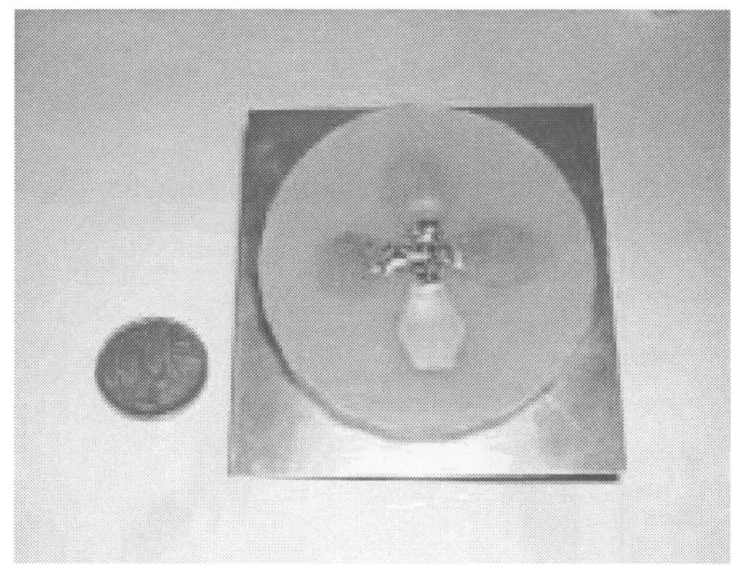

Figure 6. Photograph of the printed wideband crossed dipole antenna with planar reflector.

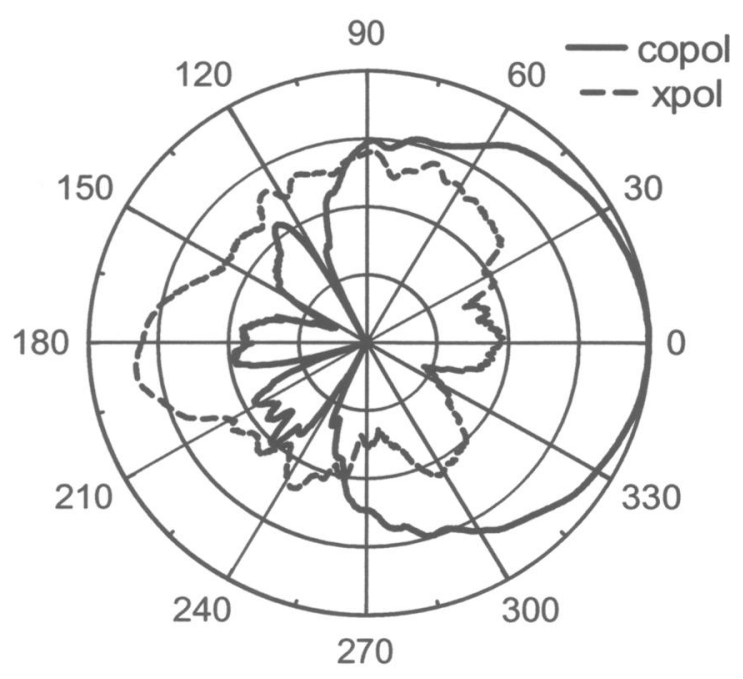

Figure 7. Normalised radiation pattern for the $x y$ plane (10 dB per division)

Circular polarisation is achieved by exciting each dipole port with equal magnitude, but with a phase difference of \pm 90 degrees, depending on whether right-hand circular polarization (RHCP) or left-hand circular-polarization (LHCP) is required. 


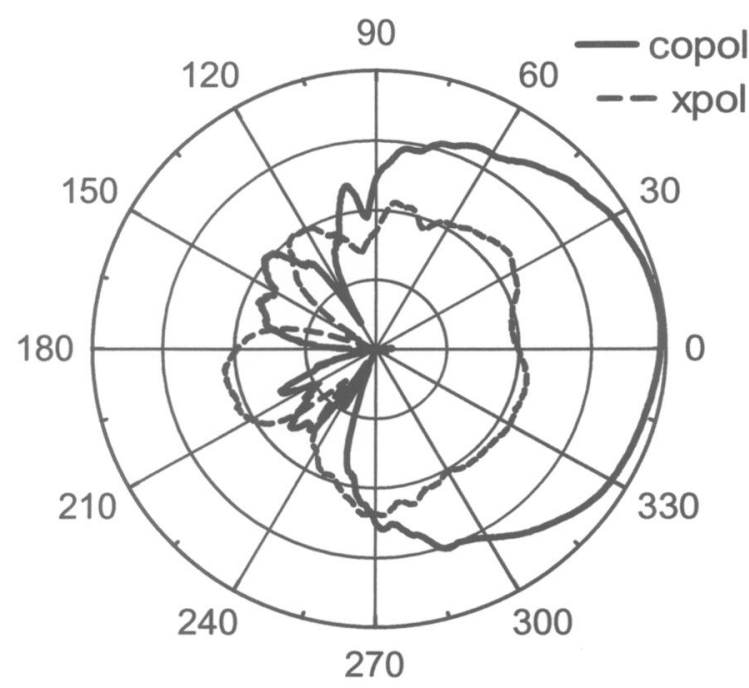

Figure 8. Normalised radiation pattern for the $x z$ plane (10 $\mathrm{dB}$ per division)

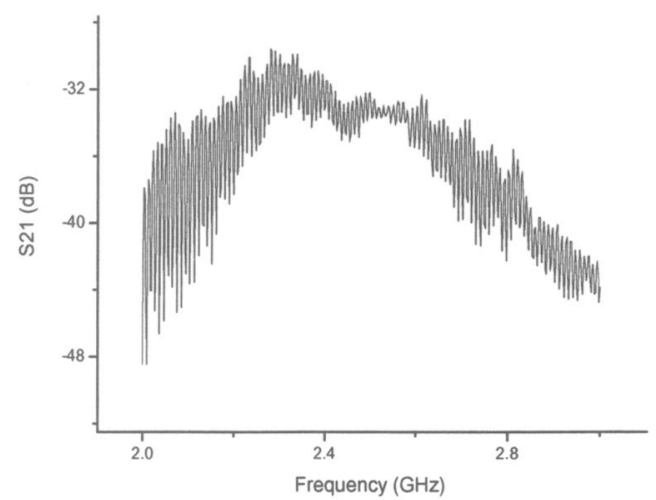

Figure 9. The measured axial-ratio is less than $4 \mathrm{~dB}$ from $2.4 \mathrm{GHz}$ to $2.63 \mathrm{GHz}$.

A spinning dipole is often used to examine the axialratio performance for circularly-polarized antennas. The spinning dipole was excited by one port of the Rohde \& Schwarz ZVA24 vector network analyser and port two is connected to the antenna. The analyser is frequency swept and the antenna response is shown in Figure 9. It can be seen that the axial ratio ( $\mathrm{S} 21$, in this case) is less than $4 \mathrm{~dB}$ from $2.4 \mathrm{GHz}$ to $2.63 \mathrm{GHz}$. The spinning dipole pattern is shown in Figure 9. The axial ratio is less that $3 \mathrm{~dB}$ over a beamwidth greater than 130 degrees.

\section{$\mathrm{V}$ CONCLUSIONS}

A wide bandwidth for a printed crossed-dipole has been achieved by optimising wing geometry, without significant degradation of port-to-port isolation, crosspolar performance, gain or circularpolarization performance. The antenna has a gain of $6.5 \mathrm{dBi}$, a front-to-back ratio of $20 \mathrm{~dB}$, over the frequency range of $2.2 \mathrm{GHz}$ to $2.7 \mathrm{GHz}$, for linear polarizations. The antenna produced circularlypolarized waves with an axial ratio less than $4 \mathrm{~dB}$, from $2.4 \mathrm{GHz}$ to $2.63 \mathrm{GHz}$ as shown in Figure 8 . The measured port-to-port isolation is greater than $20 \mathrm{~dB}$ over this range. Figure 10 illustrated the spinning dipole pattern taken at $2.53 \mathrm{GHz}$.

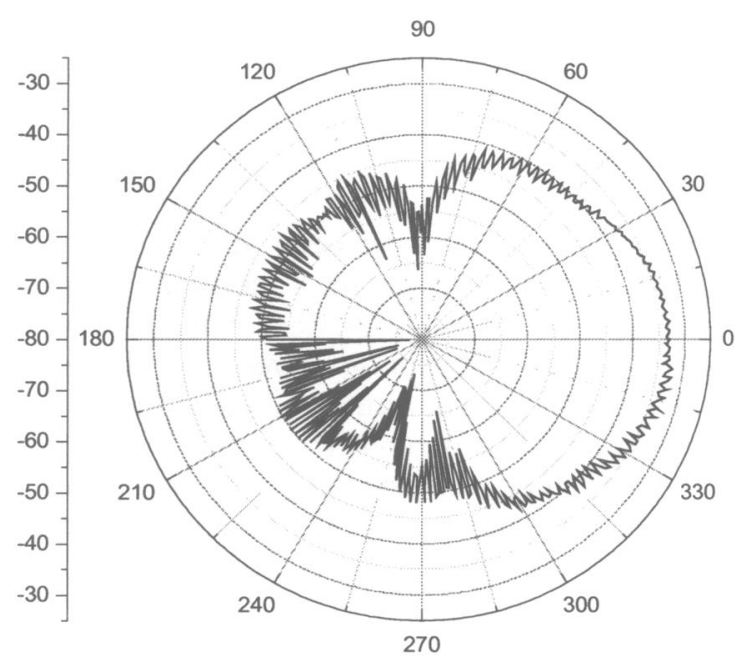

Figure 10. The measured axial-ratio is less than 3 $\mathrm{dB}$ over a beamwidth greater than 130 degrees. (scale dB)

\section{REFERENCES}

1. Faton, T. and Craig, A.G., 'Design of BroadBand and Dual-Band Antennas Comprised of SeriesFed Printed-strip Dipole Pairs', IEEE Trans. Antennas and Propagat. 2000, 48, (6), 895-900

2. Huey-Ru C., Liang-Chen K., Chi-Chang L. and Wen-Tzu C., 'A 2.4 GHz Polarization-diversity Planar Printed Dipole Antenna for WLAN and Wireless Communication Applications', Microwave Journal, 2002, Sept,.895-900.

3. Herscovici, N., Leon Lerma, F, Ammann M. J, A New Architecture for a Multi Polarized, Perpendicularly-Fed, Radiating Element IEEE International Antennas \& Propagat. Symp. Dig. 2005, (3A), 487-490.

4 Nesic, A, Jovanovic,S, a nd Radovic, I, Wideband Printed Antenna with Circular Polarization, IEEE International Antennas \& Propagat. Symp. Dig. 1997, 1882-1885.

5. Kraus, J., Antennas, MacGraw-Hill, London, 2000 pp. 238-244

6. Johnson, R. C., Jasik, H., Antenna Engineering Handbook, 2nd Ed., McGraw-Hill, pp. 4-5 and 4-17 7. Hallen E., 1938, Theoretical investigations into the transmitting and receiving qualities of antennae, Nova Acta Regiae Soc. Sci. Upsaliensis, Sec. IV, 11, No. 4, 1-44. 